who is responsible for the Education Department of Government, I am, perhaps, officially designated for this position. I need hardly say that I shall find it somewhat difficult to give very constant attention to the duties which will devolve upon the Committee. I trust, however, that the General Committee will be relieved of any work of a detailed character by the Executive Committee which you have just appointed. However, I can only assure you that any further services which I am able to give to this cause will be very cheerfully rendered, and I think I may conclude by congratulating you on the character of the proceedings which have taken place this afternoon. I assure you I feel it a very high honour indeed to have been permitted to preside on such an occasion, and over a meeting containing so many distinguished persons as those who have assembled here this afternoon.

The meeting then adjourned.

Since the meeting of the General Committee, two meetings of the Executive Committee have been held. At the first of these, at which Lord Shand accepted the office of chairman, it was reported that a number of foreigners of eminence had expressed a wish to be associated with the proposal to commemorate Mr. Huxley's distinguished services to humanity. It was resolved, in the first instance, to invite subscriptions from the members of the General Committee. At the second meeting, held on Wednesday last, it was reported that the subscriptions, which at the general meeting had amounted to 6557 , had been increased to about $£ \mathrm{I} 400$, and it was resolved that a wider appeal for subscriptions should now be made to the friends and admirers of Mr. Huxley amongst the general public. The Honorary Secretary stated that in America committees were in the course of being formed to promote the realisation of an adequate Fund. The Committee resolved to communicate, by means of a Sub-Committee of their number, with Mr. Onslow Ford, R.A., who had the advantage of being well acquainted with $\mathrm{Mr}$. Huxley, in reference to the statue, which it is proposed should be erected beside those of Darwin and Owen in the Natural History Museum, South Kensington. The extent to which the Committee may be able to carry out the other intended objects of founding exhibitions, scholarships, and medals for biological research and lectureships, and possibly in assisting the republication of Mr. Huxley's scientific works, will of course depend on the subscriptions which may now be received. These may be sent to the Treasurer, Sir John Lubbock, or the Bankers, Messrs. Robarts, Lubbock, and Co., I 5 Lombard-street, E.C. ; or to the Secretary, Prof. G. B. Howes, Royal College of Science, South Kensington.

The amount received to December 20 was $£ \mathbf{1 5 3 5}$.

The court of the Fishmongers' Company, in consideration of the eminent and important services rendered by Huxley to the cause of technical education, has agreed to give a scholarship of $£ 60$ per annum to the City and Guilds of London Technical College, Finsbury, to be called " the Fishmongers' Company's Huxley Scholarship," to be held for three years by any scholar who has given evidence of high scientific attainments, to enable him to proceed to the Central College at Kensington.

\section{RELATIONS OF THE WEATHER BUREAU TO THE SCIENCE AND INDUSTRY OF THE UNITED STATES.}

$\mathrm{IT}$ is a matter of much pleasure to me that $\mathrm{I}$ am allowed the privilege of speaking at a joint session of this Associationrepresenting as it does within the confines of its admirable organisation the scientific thought of our country. This is the Mecca towards which annually journey all those who wish, each to contribute his mite to the sum of human knowledge; each inspired with an ambition to add even one flickering ray to the great luminous orb which to-day is shedding the benign light of wisdom even unto the uttermost recesses of the earth ; subduing the barbarous instincts of man, and warming and invigorating into life the better impulses of his nature. Thus is civilisation advanced, and thus is humanity elevated to higher and higher planes of existence.

I hope to be a worker in the ranks of this great army, and as the science of meteorology can hardly be said to have passed

1 Read before the American Association for the Advancement of Science, at the Springfield Meeting, by Prof. W. S. Moore, Chief of the U.S. Weather Bureau. (Reprinted from Science.) beyond the embryonic state, I feel that the realms of investigation are boundless, and that the opportunities are correspondingly great.

As the Chief of the greatest meteorological system in the world, and with the power to control, under the direction of the Secretary of Agriculture, not only its executive functions, but the lines of future scientific investigation, I fully realise the great responsibility that rests upon me, and that at the bar of public and scientific opinion I shall, in the years to come, justly be held to a strict accountability for my stewardship.

Before considering the lines of investigation which can consistently be prosecuted by the Weather Bureau, it will be well to note the law which perscribes the duties of the Chief.

By an Act Congress approved October I, I89o, Sec. 3, Statutes at large, Fifty-first Congress, p. 653, it is provided :

"That the Chief of the Weather Bureau, under the direction of the Secretary of Agriculture, on and after July I, I89r, shall have charge of the forecasting of weather, the issue of storm warnings, the display of weather and flood signals for the benefit of agriculture, commerce and navigation, the gauging and reporting of rivers, the maintenance and operation of sea-coast telegraph lines, and the collection and transmission of marine intelligence for the benefit of commerce and navigation, the reporting of temperature and rainfall conditions for the cotton interests, the display of frost and cold wave signals, the distri bution of meteorological information in the interests of agriculture and commerce, and the taking of such meteorological observations as may be necessary to establish and record the climatic conditions of the United States, or as are essential for the proper execution of the foregoing duties."

It will be seen that the main object for the existence and continuation of this Bureau is to give warning of the approach of storms, and therefore that the proper line of investigation should be for the purpose of determining the true philosophy of storms. The goal to be striven for is the improvement of weather forecasts, and surely one of the pre-requisites to determine coming events is a thorough knowledge of existing conditions.

To those who have read every important treatise on meteorology, and who have studied every text-book on the subject, it is painfully patent that we are extremely ignorant of the mechanism of storms, of the operations of those vast and subtle forces in free air which give inception to the storm, and which supply the energy necessary to accelerate cyclonic action when formed, or to disperse the same when fully in operation. We know that great atmospheric swirls in the shape of high and low pressure areas alternately drift across the country at intervals of two or three days; that the atmosphere flows spirally into the cyclonic or low-pressure system and outward from the anticyclonic or high-pressure system, that the in-drawn east and south winds on the front of the storm are warm, and that the inwardly-flowing north and west winds are cold.

The theories of Redfield, Espy, Loomis, Ferrel, and others, teach that our great storms are composed of immense masses of air gyrating about a vertical or nearly vertical axis, drifting eastward, and at the same time drawing in warm easterly currents at the front, and cold westerly currents at the rear ; that the commingling of these two as they rise to greater and greater elevations, near the regions of the cyclonic centre, throws down volumes of rain or snow; that as precipitation occurs with the ascending currents, the heat of condensation energises the cyclonic circulation; that the air at the centre of the storm is relatively warm, is rarefied by centrifugal force, and by reason of less density, rises to a great elevation, and in the upper regions of the atmosphere flows away laterally to assist in building up high-pressure areas on either side.

The high and low pressure areas are supposed to be carried eastward by the general easterly drift of the atmosphere in the middle latitudes, somewhat as eddies are carried along by water in a running stream.

But, unfortunately for the complete accuracy of these theories, the forecaster often finds heavy downpours of rain without any cyclonic circulation, and no convectional system in operation again over immense areas of country, especially in the Rocky Mountain region, for many months in the year condensation occurs not at all in the warmer easterly currents flowing into the storm centre, but almost exclusively in the westerly portion of the storm area, where the cold north and west winds are flowing in.

Again, many investigators to-day have good reason to doubt

NO. 1365 , VOL. 53$]$ 
that the centre of the storm is warm to any great elevation, or that cyclonic circulation obtains to the top of the air.

In outlining, in a rough and general way, the line of investigation which in my judgment promises to give the most prolific results, not only to the cause of meteorological science, but to the making of more accurate forecasts for the benefit of agriculture and commerce, I will say that we have been for years taking our measurements at the bottom of this great ocean of air, while the forces which cause the formation of storms, and which influence their intensity and direction of motion, operate at great elevations, or are extraneous to our earth. It therefore seems imperative that systematic exploration should be made of the upper air. Balloon ascensions should be made in the several quadrants of the cyclonic storm, and also at the centre thereof, especially when rain is falling and the barometric gradient is steep. It is especially important to know the level at which condensation ceases, the depth of the cloud stratum, the temperature gradient, the air pressure and humidity, to a height of four or five miles. Skilled aëronauts with complete and accurate instruments should be placed in the region of severest action at the season of the year when storms are most frequent. They should be held in readiness until the approach of storms typical of cyclonic action, and then from the central office, where the movement of the storm is being carefully watched on the daily synoptic chart, they should be given telegraphic orders to ascend, and their ascensions should be so timed as to secure accurate readings at great elevations throughout the several quarters of the storm. It is believed that information thus secured will establish something like an approach to the true philosophy of storms, in contradistiction to the very imperfect theories which too often are hastily approved as demonstrated principles. Instead of erecting a cumbersome superstructure upon the sand, let us endeavour to lay a corner-stone upon which to erect something exact enough to be called a science.

In winter the great high-pressure areas which constitute our cold waves should receive the same thorough exploration. Readings at Pike's Peak or Mount Rainier might be useful in this investigation, but they are too far removed from the general track of storms and cold waves to furnish the full information desired.

Upper-air explorations may be accomplished by a train of kites carrying automatic instruments, by captive kite-balloons which may be forced nearer and nearer the zenith with increasing wind velocity, or by the ascension of trained observers in free balloons. We must strive for the perfection of appliances and instruments which will, at no distant day, enable us to present to the forecaster the charted synchronous meteorological conditions prevailing at high levels and covering a great area Mr. McAdie, at Washington, has secured recently some good records with kites at elevations from 1000 to 2000 feet.

Systematic exploration of the upper air, with a continuation of the studies begun by Prof. Bigelow of terrestrial magnetic forces as induced by the solar magnetic field, will be the line of investigation prosecuted during the next two years, and from which it is hoped that results satisfactory to the practical as well as the theoretical man may be obtained.

The Secretary of Agriculture is in thorough sympathy with all lines of research which can be legally carried on under the Act of Congress constituting the Weather Bureau, and which promise to give results useful to the people.

Harmonious co-operation between the practical worker and the scientific investigator is essential to success. Too often they have found themselves picking out diverging paths. In the future they will work on parallel and converging lines, and not far removed from each other, and the result, I am confident, will be beneficial to all. In a great system like ours, each worker must be justly recognised for the merit that is in him, whether he be a skilled scientist or an able executive officer, and he should be given his proper place as an integral part of the great whole which constitutes the efficient Bureau.

A brief retrospect of the forecast work may not be without compensating results in our efforts at future improvements.

Forecasts were begun in the United States about twenty-five years ago, and have, during the past decade, become of such benefit to the many and diversified interests of the country that, with one accord, the people now acknowledge their value, and applaud all efforts to improve and extend their usefulness. Fifty million dollars is a low estimate of the value of property placed in jeopardy by one West Indian hurricane sweeping up our Atlantic coast.

Predictions were first called "probabilities," and were made for districts, each comprising several States, and included a prediction as to the probable change in barometer. Later the prediction as to barometer was omitted. Forecasting by districts was soon shown not to be specific enough as to boundary, anc the designations applied were not well understood by the people; hence forecasting by States was adopted.

Forecasts were made only at the Central Office at Washington, and the local observers were allowed to disseminate no other, nor to give public expression to any opinion of their own which might be construed into a forecast. Considering the very limited training of the observers, and the lack of all chartered meteorological conditions for their study and enlightenment, the wisdom of that regulation could hardly be questioned.

With the transfer of the Weather Bureau to the Department of Agriculture, came the inauguration of far more liberal and progressive ideas. The office of Local Forecast Official was created for such observers as had shown special fitness for forecast work, and they were assigned to duty at the more important agricultural, commercial, or maritime centres, with instructions to carefully study the local climatology of their sections, so that products that are indigenous to limited areas, or interests which are of special importance to particular sections, might have such application of the weather forecasts as the intimate personal attentions of a competent local official could give.

The changes enumerated have been carefully tested and found to be beneficent in purpose, and worthy of continued and per. manent application. Thus has the forecasting system of to-day slowly developed during the past twenty-five years. Is it not the essential feature of the Weather Bureau? Is it not the nucleus around which all departments of thought and study must rotate and become auxiliary, if the original intent of Congress, made manifest by the establishment of a national storm-warning system, is to be carried forward to as successful an operation as the present knowledge of the physics of the air will permit? It is hoped that discoveries may be made relative to the controlling and modifying forces of storms which shall raise the standard of forecasting accuracy attained by our most expert officials, who have had all the benefits to be derived from many years of patient and intelligent observation of storms, from the time of their inception in, or entrance within our daily observed and charted territory, until they have been dissipated or have passed eastward beyond our range of vision.

It may be well to consider what class of forecasts can be most successfully made by our more or less empirical methods, the object being to extend the work along such lines of activity as promise the most beneficial results.

As to this proposition it is doubtless conceded by all that when pronounced high and low-pressure areas dominate the weather conditions and the changes in wind, temperature and weather are characterised by such force and degree as to render them destructive to lives and property, a forecaster of average ability and well-balanced judgment is able to make nearly or quite as accurate a forecast as when the air pressure is quite uniformly distributed and all changes of weather are so slight as to be of no importance.

If, then, a destructive frost or cold wave can be predicted as easily as a change of a few degrees in temperature, and if the coming of high winds and gales are as easily foretold as that of a gentle zephyr, it is evident which class of forecasts should receive the greater attention. The public care comparatively little for predictions of moderate changes, and but little credit attaches to the Bureau when such forecasts are verified; but when great heat, cold waves or violent winds are on the programme, a vital interest is felt in the subject, and the accurate forecasting of such conditions is the gauge by which the public measures the usefulness of the Bureau.

Horticulturists and the growers of tobacco and cranberries realise the vast benefit to be derived from accurate frost predic tions, and I will give a brief statement of what I believe to be original ideas introduced into the making of frost forecasts while in charge of the State Weather Service of Wisconsin, a State including within its domain the largest area of cranberry marshes in the world, and also including an extensive area devoted to the cultivation of tobacco. Heretofore I believe that only the air conditions have been taken into consideration in the making of frost forecasts-such as pressure, temperature, relative humidity, cloudiness, and wind velocity. As a result of my investigations, systematically prosecuted for three years, I found that the conditions of the soil were equally as important as those of the air.

NO. I 365 , VOL 53$]$ 
When the high-pressure area is moving in from the west, clear and colder weather anticipated, with the probability that the early morning temperature will permit the formation of frostthe most important elements to be considered, in determining whether or not frost will occur injurious to growing crops-are as follows :

(I) Has rain recently fallen, and what is the condition of the soil relative to the amount of moisture contained?

(2) What are the natural properties of the soil relative to the slow or rapid loss of heat by radiation?

(3) To what degree of heat has vegetation been subjected during the period immediately preceding?

The early fall frost injurious to tender crops occurs with the observed town or telegraph minimum temperature ranging from $40^{\circ}$ to $50^{\circ}$, because, when the early morning temperature in the town falls much lower than $40^{\circ}$, it is usually so late in the season that all crops are gathered, or, if not gathered, they have been destroyed ere this condition arrives. At the time, then, that frostwarnings are of the most benefit, we have to deal with the air at temperatures considerably above the freezing-point, and to recall that a deposition of frost requires that the temperature of the top soil, or that of vegetation, be reduced to the freezing point. This, of course, is accomplished by conduction and radiation of heat, which takes place more rapidly from the soil and vegetation than it does from the lower stratum of air to the higher.

Anything that will seriously interfere with a rapid loss of heat after nightfall will tend to prevent the formation of frost. Moisture does this, and if the soil be well charged it partakes greatly of the stability of water as to temperature, and cools but little, if any, below the temperature of the superincumbent air, and no frost will occur even though all other favourable conditions of clearness, gentle winds, and cool air obtain. Even a small amount of moisture, say one-half inch of rainfall, will give ample protection if well distributed and precipitated within the twenty-four hours previous. But when severe drought conditions are prevalent, injurious frosts may occur when the telegraphic temperatures do not show a reading within ten degrees as low as in the first case.

I believe that, when estimating the probability or severity of frost, sufficient weight has not been given to the dryness or wetness of the soil, and the resultant dissipation or conservation of heat, and I call special attention to the point as one of the means for improving the forecast.

I have in mind two typical cases. In the first a high-pressure area attended by clear and cool weather drifted from the westward until it covered the State. No rain had fallen with the passage of the low-pressure area immediately preceding it; hence the ground was in excellent condition for the rapid loss of heat during the night, and a consequent lowering of the temperature of vegetation to the freezing point. Considerable damage was done to cranberries in unflooded marshes. In the second case a high-pressure area of slightly greater weight and slightly lower temperature covered the region about ten days later, but it was preceded within a few hours by a light but welldistributed fall of rain, averaging about one-half an inch, and no frost occurred. In both cases the wind was gentle from the north-west, and the nights were clear. With slightly lower air temperature and higher barometer in the second condition, heavier frost would have occurred than in the preceding case, had it not been for the thinly spread moisture of the timely rain conserving heat at the surface of the earth.

Might not this principle be carried further in the improvement of the forecast? Assuming that the caloric energy of the sun is a constant factor, the earth receives each year the same amount or intensity of heat, and as the atmosphere is warmed mainly by contact with or radiation from the earth, seasonal variations of temperature which are marked departures from the normal might result from abnormal terrestrial surface conditions with respect to the conservation of this constant solar energy over large continental areas. Flere the excessive or deficient rainfall during the preceding seasons should receive careful consideration. The subject is one that requires deeper and more detailed investigation than the length of this paper will permit.

I find that the minimum temperatures in cranberry marshes during abnormally dry seasons often fall $15^{\circ}$ below the temperatures telegraphed from the cities and towns within a few miles of the marshes. This is due to the fact that when the loose, spongy peat, of which the marsh is composed to the depth of several feet, has dried out, the radiation of heat during the night is very rapid, and is not counterbalanced by conduction and connection from the marsh. The temperature, therefore, in cranberry marshes is at all times much lower than that which obtains in marshes composed of heavy black muck, where it preserves a more equable condition, such as is common to air resting over a considerable body of water. A dry cranberry marsh does not, therefore, enjoy that immunity from frost enjoyed by wet marshes and watery lands. But when the ditches are flooded from the reserve water supply on receipt of a frost warning, the water quickly percolates through the peat composing the marsh, and the rapid loss of heat by radiation is checked and the frost averted.

The amount of heat to which vegetation has been subjected immediately before the frost condition, and the temperature under which it had made its growth, will in a great measure determine the extent of damage to ensue.

By carefully considering the principles herein enunciated, I will say that in 1894 , twelve out of fourteen official forecasts of frost were fully verified-a much greater percentage of accuracy than has ever been attained by simply considering air conditions. alone.

\section{UNIVERSITY AND EDUCATIONAL INTELLIGENCE.}

ON Friday, the Chancellor of the Exchequer received at tho Treasury a large deputation in support of a memorial praying that increased aid may be given to the English University Colleges, ten in number, and to University College, Dundee, which at present receive among them an annual grant of $£_{1} 5,000$. Sir M. Hicks Beach, in reply, said there was no question that the existing grant of $\mathcal{L}_{\mathrm{I} 5}$, 000 would be continued ; but he thought that in accordance with the recommendations of two Parliamentary committees a competent inspector should be appointed to visit annually each college receiving a grant, and report on its efficiency, its success, and its financial position. Till such an inspector should have reported, he did not think it possible for him to consider the increase of the grant.

IT is satisfactory to be able to note that the question of the education of mine managers, assayers, and engineers in Australia is actively discussed in the most recent Government reports on mines for several of the Colonies. In Victoria, mining schools have long been established at Ballarat and Bendigo, with branches at the more important mining centres in the Colony. Certificates of competency to act as mine managers are given by these schools, although the holding of such by mining engineers is not compulsory by law. In like manner in Tasmania, similar certificates are given after a Governmental examination. As the UnderSecretary for Mives of Queensland observes in his latest annual report, "the implication is that a certificated mining manager is preferable in the eye of the law to one who has no such creden. tials." In 1893 a school of mines in connection with Sydnev University was founded by the New South Wales Government, and $£$ Io, ooo spent in the erection of a suitable building, which has just bcen completed. The teaching staff has been formed at a small cost by utilising the services of the professors paid by the University, and lectu es and practical instruction are now being given in chemistry, metallurgy, assaying, geology, mineralogy, and all branches of mining to an increasing number of students. Up to the present Queensland alone, among the more important Colonies, has established no mining school; but, State aid having been p omised to well-supported schemes in any mining centre, the reproach will probably soon be removed. Indeed, some progress has already been made towards establish. ing a technical school at Brisbane. With regard to the effect of such schools, the Under-Secretary of Mines for New South Wales remarks, in his Report for 1894 : "It is hoped that the establishment of the School of Mines will result in the giadual improvement in the methods of mining, as practised in this Colony, by providing a class of managers who will have had the advantage of a thorough scientific training, and who will only need a few years' practical experience to qualify them as mining engineers of the highest efficiency. The ultimate result must be an increased development in the mining industries of this country." In view of this feeling on the part of the Government officials of the various Colonies, it is evident that the compulsory possession of a certificate of competency by Australian mine managers is almost within sight.

NO. I 365 , VOL. 53] 